Revista Brasileira de Biblioteconomia e Documentação

(c) (i) \&)

Esta obra está licenciada sob uma licença Creative Commons Atribuiç̧ão - NãoComercial 4.0 Internacional.

\title{
REFERÊNCIA
}

LOPES, Paulo Roberto Danelon; ARAÚJO JÚNIOR, Rogério Henrique de; PERUCCHI, Valmira. Análise bibliométrica dos grupos de pesquisa em inteligência competitiva no Brasil. Revista Brasileira de Biblioteconomia e Documentação, São Paulo, v. 13, n. 2, 2017. Disponível em:

https://rbbd.febab.org.br/rbbd/article/view/451/646. Acesso em: 23 jan. 2019. 


\section{ANÁLISE BIBLIOMÉTRICA DOS GRUPOS DE PESQUISA EM INTELIGÊNCIA COMPETITIVA NO BRASIL}

\author{
Paulo Roberto Danelon \\ Lopes \\ Doutorando em Ciência da \\ Informação pela Universidade de \\ Brasília. \\ E-mail: \\ paulodanelon@yahoo.com.br
}

Rogério Henrique de Araújo Júnior

Professor na Faculdade de Ciência da Informação da Universidade de Brasília

E-mail: araujojr@unb.br

\section{Valmira Perucchi}

Bibliotecária-Documentalista no Instituto Federal de Educação, Ciência e Tecnologia da Paraíba E-mail: vperucchi2@yahoo.com.br

\section{RESUMO}

Em razão do aumento da competitividade do mercado as organizações precisam estarem sempre monitorando o ambiente no qual estão inseridas e se reinventando para atender as novas demandas dos clientes e sobreviverem. A Inteligência Competitiva é uma peça fundamental nesse processo. 0 objetivo do presente trabalho foi analisar, quantitativamente, na área de Inteligência Competitiva, os pesquisadores existentes, a distribuição geográfica dos grupos pelas diversas regiões e estados da Federação, linhas de pesquisa e a produção científica, com o propósito de levantar dados capazes de permitir o início da montagem de um mapa da pesquisa acadêmica nesse importante campo da gestão do conhecimento no Brasil. A metodologia utilizada na elaboração desse artigo fundamentou-se nos estudos bibliométricos. A coleta dos dados ocorreu no Diretório de Grupos de Pesquisa do CNPq por ser uma fonte de dados e de informações extremamente propícia para uma análise bibliométrica dos grupos de pesquisa, especificamente, em inteligência competitiva no Brasil, já que congrega os limites e o perfil geral da atividade científicotecnológica, fornecendo informação precisa e validada sobre quem realiza pesquisa no Brasil. Buscou-se traçar um pequeno mapa das linhas de pesquisa complementares ao tema da inteligência competitiva que aparecem nos grupos de pesquisa, constatou-se que a quantidade de artigos, bem como de livros e capítulos de livros publicados foi diretamente proporcional à quantidade de pesquisadores por grupo e que há uma concentração dos grupos mais produtivos em três unidades da federação, respectivamente: São Paulo, Brasília e Santa Catarina.

Palavras-chave: Bibliometria; Inteligência competitiva; Grupo de Pesquisa em Inteligência Competitiva do CNPq. 


\title{
BIBLIOMETRIC ANALYSIS OF RESEARCH GROUPS IN COMPETITIVE INTELLIGENCE IN
}

BRAZIL

\begin{abstract}
Because of the increased market competitiveness organizations need to be always monitoring the environment in which they operate and reinventing themselves to meet the new demands of customers and survive. Competitive intelligence is a key player in this process. The objective of this study was to analyze quantitatively the Competitive Intelligence area, existing researchers, the geographical distribution of the groups by different regions and states of the country, lines of research and scientific production, in order to collect data that would permit the beginning of the assembly of a map of academic research in this important field of knowledge management in Brazil. The methodology used in the preparation of this article was based on bibliometric studies. Data collection occurred in the $\mathrm{CNPq}$ Research Groups Directory to be a source of data and extremely favorable information to a bibliometric analysis of research groups, specifically in competitive intelligence in Brazil, as it brings together the limits and the general profile the scientific and technological activity, providing accurate and validated on who conducts research in Brazil. We attempted to draw a small map of the complementary lines of research the topic of competitive intelligence appearing in the research groups, it was found that the number of articles and books and chapters of books published was directly proportional to the number of researchers per group and that there is a concentration of the most productive groups in three Brazilian states, respectively: São Paulo, Brasilia and Santa Catarina.
\end{abstract}

Keywords: Bibliometrics, Competitive, Research Group on Competitive Intelligence CNPq.

\section{INTRODUÇÃO}

Diante de um mercado cada vez mais acirrado, um dos maiores focos de qualquer organização deve ser a manutenção de sua entropia negativa. Inúmeras são as áreas do conhecimento que podem influenciar nesse processo, a Inteligência Competitiva (IC) faz parte desse espectro, uma vez que poderá propiciar os 
subsídios necessários ao levantamento das oportunidades e ameaças existentes no ambiente externo das organizações bem como dos pontos fortes e fracos do ambiente interno necessários à execução do planejamento, pois fará com que a organização esteja atenta as nuances que acontecem nos cenários político, econômico, social e tecnológico.

A Inteligência Competitiva, não obstante as diversas definições propostas quando da sua popularização como técnica a partir da década de 1990, está assentada em um conceito de capital importância que define o seu escopo de aplicação. Trata-se da Vantagem Competitiva, termo cunhado por Michael Porter para definir o valor que uma empresa cria para os seus compradores e que ultrapassa os seus custos de fabricação. A concepção proposta por Porter (1985) tornou-se clássica para explicar as regras que moldam a Vantagem Competitiva que está apoiada no valor que o cliente atribui a um dado serviço ou produto e paga por isso.

$\mathrm{Na}$ formação do valor são considerados dois tipos básicos: por liderança de custos e por diferenciação. A liderança de custo se refere à vantagem competitiva que uma empresa adquire quando os seus custos na oferta de serviços ou na fabricação de produtos são menores do que dos seus concorrentes. A liderança por diferenciação diz respeito à agregação de valor que uma empresa incorpora aos seus produtos e serviços diferenciando-os dos seus concorrentes.

A inteligência, quando considerada em plano mais amplo, aponta tradicionalmente para atividades relacionadas à espionagem, grampos e obtenção ilegal de informações sensíveis. Quando se envolve à questão da competitividade, o escopo da inteligência pode ser firmado da seguinte forma: capacidade de utilização das informações obtidas de forma legal e ética em prol de uma posição competitiva ou como propõe Fuld (2010), associação entre a habilidade para prospectar a informação correta e a capacidade de visualizar e interpretar os transtornos impostos pelos concorrentes. Em suma, as ações de IC proporcionam a identificação de informações dos concorrentes por meio do monitoramento constante do mercado, quer seja por meio da prospecção e da vigilância tecnológica, quer seja pela identificação de oportunidades em eventos, feiras, seminários, congressos ou reuniões de negócio. 
De acordo com Perucchi e Araújo Júnior (2012) e Dou e Manullang (2004), a IC está relacionada às atividades que permitem o monitoramento do ambiente organizacional por meio da busca, análise e disseminação de informações e sua base de funcionamento é a informação- fator crítico de sucesso para a sobrevivência e diferenciação das organizações no ambiente competitivo. A informação deve ser compreendida aqui como um conjunto de ações orientadas para um fim, englobando os seguintes elementos: geração, transmissão, armazenamento e busca com o objetivo de reduzir a incerteza no processo decisório. Para a implementação de ações de IC as informações podem ser classificadas por tipos, dentre eles destacam-se informações tecnológicas sobre: clientes, concorrentes, legislação, produtos, ações políticas, de caráter demográfico, entre outros.

De modo geral, os modelos de IC que as organizações devem conceber envolvem três elementos básicos: dados, informação e inteligência. Esses elementos visam transformar a informação em produto útil ao processo decisório resultante de organização e análise.

$\mathrm{Na}$ figura 1, apresenta-se a correlação destes elementos básicos na perspectiva das atividades dos analistas de inteligência competitiva.

Figura 1- Atividades dos analistas de inteligência competitiva

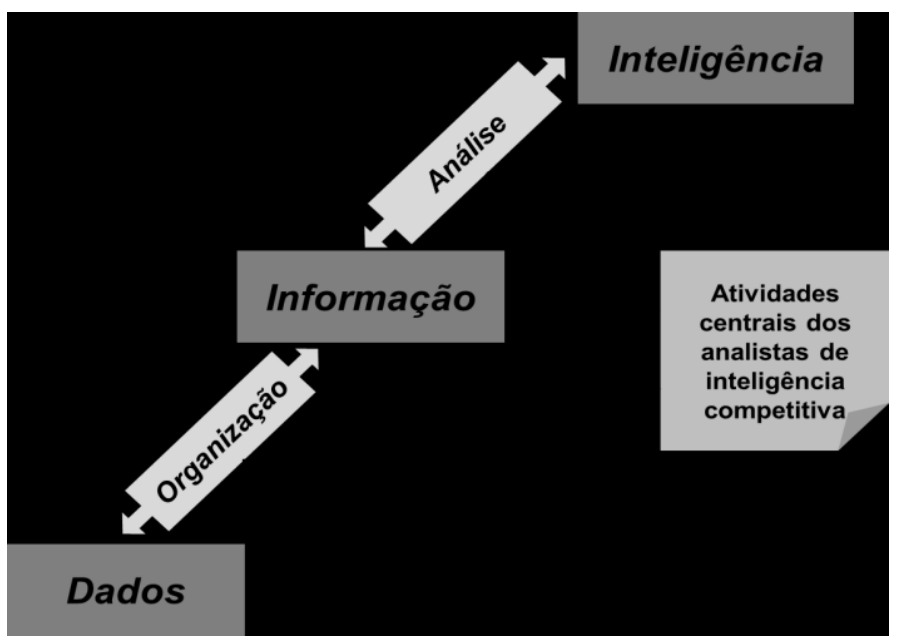

Fonte: Autores

0 resultado final que se espera da implementação de um modelo de IC é a oferta de informação que reflita a organização de dados sobre os meios ambientes, 
bem como a análise da informação sob a perspectiva temporal que envolve passado, presente e desenvolvimento futuro das organizações, ou seja, a oferta de informação incorporada.

Outra etapa importante que deve ser ajustada à proposta de modelos de IC é a geração de conhecimento. Essa etapa é o resultado da gestão dos dados e da informação, por meio de tarefas específicas de agregação de valor à informação.

No âmbito da Inteligência Competitiva, os modelos de gestão da informação antecedem a construção da base de conhecimento que congregam ações de identificação e uso de fontes de informação para apoiar o posicionamento competitivo das organizações, considerando a informação e o seu uso, segundo Drucker (1999), como instrumento para a criação de riqueza nas organizações. Tendo por base tal concepção, esses modelos subsidiam com insumos de informação a interpretação e análise das informações coletadas, transformando-as em conhecimento estratégico para o posicionamento competitivo das organizações, que de outra forma acabam por trazer valor adicional à análise, entendida como atividade central do processo de IC.

O fator crítico de sucesso para o modelo de Inteligência Competitiva é o seu posicionamento na estrutura das organizações de modo a apoiá-las nas atividades estratégicas de monitoramento do mercado. Para que esse fator se cumpra, todo o processo de IC deve estar posicionado no âmbito do planejamento estratégico das empresas, a fim de alcançar os seus objetivos: monitorar sistematicamente o ambiente concorrencial e promover a contra-inteligência que corresponde às medidas adotadas pelas organizações para proteger as suas informações estratégicas (informações sensíveis) que podem ser alvo de atenção das empresas concorrentes.

Dentre as ações oriundas do trabalho de Inteligência Competitiva, pode-se citar algumas das vantagens que a corporação, que monitora o seu ambiente concorrencial, pode auferir: selecionar dentre grandes volumes de informações, aquelas que de fato serão úteis ao processo de identificação das ações da concorrência; perceber e registrar movimentos estratégicos das empresas concorrentes; obter e consolidar um panorama preciso do contexto de atuação da empresa e identificar e registrar sinais da atuação dos concorrentes, a fim de 
promover ações de antecipação para prevenir as ameaças e aproveitar as oportunidades garantindo assim sua entropia negativa.

Apesar de a inteligência, na concepção de Martins, Ferneda e Martins (2008) ser a única vantagem competitiva não esgotável (auto-sustentável) para corporações e instituições, as ações de IC possuem limitações de ordem ética e legal. 0 estabelecimento de uma relação segura e de confiança entre a organização e os seus concorrentes deve ser pautado pela fidedignidade das informações fornecidas e pelos meios lícitos para se conseguir tais informações, além da ampla consideração dos princípios éticos que devem orientar o trabalho dos analistas de IC: legalidade, moralidade e impessoalidade.

Diante da importância dessa ferramenta para as organizações elencadas nos parágrafos anteriores, este artigo teve como objetivo compreender as características dos grupos de pesquisa que tratam da inteligência competitiva em suas linhas de atuação e de pesquisa acadêmica. Sendo assim, foram analisados os grupos cadastrados no Diretório de Grupos de Pesquisa do Conselho Nacional de Desenvolvimento Científico e Tecnológico (CNPq) que tinham a palavra inteligência competitiva no nome do grupo ou na linha de pesquisa.

A pesquisa buscou analisar, quantitativamente, os pesquisadores, a distribuição geográfica dos grupos pelas diversas regiões e estados da Federação, as linhas de pesquisa e produção científica, com o propósito de disponibilizar subsídios para iniciar a montagem de um mapa da pesquisa acadêmica em inteligência competitiva no Brasil.

Pode-se considerar relevante que quanto mais conhecidas forem as características dos grupos de pesquisa de inteligência competitiva brasileiros maior será a oportunidade de montagem de um mapa estratégico da pesquisa acadêmica no País, já que se trata de uma área de viés ligado ao mapeamento das ações de competição entre as organizações e, por isso, de grande potencial para a inovação tecnológica, sem contar a possibilidade de apresentar um entendimento claro e conciso do desenvolvimento desta disciplina e seus desdobramentos, a fim de consubstanciar o estado da arte da pesquisa na área. 


\title{
2 GRUPOS DE PESQUISA E A INTELIGÊNCIA COMPETITIVA
}

Devido à importância da inteligência competitiva para os ambientes organizacionais, faz-se necessário conhecer os grupos de pesquisa que tratam dessa temática.

Hoffmann (2011, p. 137) define Inteligência Competitiva "de maneira ampla, como um processo de aprendizado, motivado pela competição, e baseada na informação que fortalece as estratégias da organização a curto, médio e longo prazo."

De acordo com Silva, Casimiro e Duarte (2016) o trabalho desenvolvido por um grupo é importante.

\begin{abstract}
Uma equipe empenhada liderada por pessoas altamente competentes procurando sempre posicionar no sentido de adquirir um maior conhecimento e experiência, qualificando-se a ele e o grupo cada vez mais uma condição de estabilidade e comprometimento com uma postura mais participativa objetivando e refletindo nas ações dentro da organização. (SILVA, CASIMIRO E DUARTE, 2016, p. 22)
\end{abstract}

No Brasil, os grupos de pesquisa são organizados pelo Diretório dos Grupos de Pesquisa do CNPq (2016), as informações contidas no Diretório dizem respeito aos recursos humanos constituintes dos grupos (pesquisadores, estudantes e técnicos), às linhas de pesquisa em andamento, às especialidades do conhecimento, aos setores de aplicação envolvidos, à produção científica, tecnológica e artística e às parcerias estabelecidas entre os grupos e as instituições, sobretudo com as empresas do setor produtivo. Com isso, é capaz de descrever os limites e o perfil geral da atividade científico-tecnológica no Brasil. O Diretório possui uma base corrente, cujas informações podem ser atualizadas continuamente pelos atores envolvidos, e realiza censos bi-anuais, que são fotografias dessa base corrente.

De maneira geral, de acordo com Silva, Casimiro e Duarte (2016, p. 15) “Os grupos de pesquisa são responsáveis pela investigação de temáticas relevantes no âmbito científico, conduzem o debate e acirram o saber-fazer, contribuindo, sobremaneira, para a construção de conhecimento." 
Silva, Casimiro e Duarte (2016, p. 16) desenvolveram uma pesquisa no campo da ciência da informação que teve como objetivo geral: "caracterizar os grupos de pesquisa sobre inteligência organizacional competitiva quanto aos aspectos gerais, recursos humanos e especialidades do conhecimento. " Os autores (p. 19) concluem que: "No Brasil, houve um crescimento significativo dos grupos de pesquisa trabalhando com Inteligência Organizacional e Competitiva."

Tendo por base os desafios presentes e futuros da inteligência competitiva Amaral et al. (2015, online) desenvolveram um estudo a partir das publicações em periódicos que teve como objetivo "identificar e analisar a produção científica brasileira em inteligência competitiva. Os Autores concluem que:

Nota-se a incipiência no que tange o desenvolvimento científico da IC no Brasil. As iniciativas brasileiras estão concentradas em questões voltadas à descrição de como se deve executar o processo de IC com $31 \%$ dos artigos. Em segundo lugar nota-se que, ainda, há necessidade de afirmação da área, pois $24 \%$ dos artigos buscavam afirmar a importância e as necessidades do desenvolvimento de IC para a competitividade das organizações. Nesse sentido, vale ressaltar que $14 \%$ dos artigos discutem, exclusivamente, conceitos e teorias de IC. Amaral et al. (2015, online).

Para Hoffmann (2011, p. 131) a inteligência competitiva é uma possibilidade "para os gestores e suas organizações, pois atuam buscando compreender os acontecimentos do ambiente organizacional. " Esses acontecimentos "surgem no horizonte organizacional de diferentes formas, por exemplo, com o surgimento de novas tecnologias, novos negócios, novas formas de trabalho, novos processos, novos materiais, entre outros, que modificam o cenário do ambiente organizacional."

\section{PROCEDIMENTOS METODOLÓGICOS}

Para alcançar o objetivo proposto, utilizou-se a bibliometria, que consiste em uma análise estatística de dados quantitativos. A Bibliometria para Guedes e Borschiver (2005): "é uma ferramenta estatística que permite mapear e gerar diferentes indicadores de tratamento e gestão da informação e do conhecimento, especialmente em sistemas de informação, de comunicação científicos e 
tecnológicos e de produtividade, necessários ao planejamento, avaliação e gestão da ciência e da tecnologia, de uma determinada comunidade científica ou país. "

A coleta dos dados ocorreu no Diretório de Grupos de Pesquisa do CNPq. A escolha dessa base deveu-se ao fato de os grupos serem enumerados a partir de universidades, institutos de pesquisa científica, institutos tecnológicos e laboratórios de pesquisa e desenvolvimento de empresas estatais. Essa abrangência, explicitada pelo próprio CNPq, torna o Diretório uma fonte de dados e de informações extremamente propícia para uma análise bibliométrica dos grupos de pesquisa, especificamente em inteligência competitiva no Brasil, já que congrega os limites e o perfil geral da atividade científico-tecnológica, fornecendo informação precisa e validada sobre quem realiza pesquisa no Brasil.

A busca foi pela palavra-chave "inteligência competitiva", a pesquisa no site do diretório foi realizada no mês de outubro de 2013, recuperando-se 46 grupos. No diretório dos grupos de pesquisa, as seguintes informações foram recuperadas: nome do grupo, atualização e certificação, quantidade de pesquisadores por grupo, unidade da federação, instituição ao qual o grupo está vinculado, linha de pesquisa e empresas associadas ao grupo. Pelo link do pesquisador, que consta no site do diretório de grupos de pesquisa, teve-se acesso ao currículo na Plataforma Lattes do $\mathrm{CNPq}$, para a coleta dos dados referentes à produção científica: artigos completos publicados em periódico, livros e capítulos.

Considerou-se os grupos de pesquisa que tinham a palavra "inteligência competitiva" no nome ou na linha de pesquisa. Dos 46 grupos recuperados, 14 foram desconsiderados por não apresentarem o parâmetro estipulado. Esse procedimento tornou-se relevante em virtude do foco da pesquisa.

Utilizou-se, ainda, como critério para a seleção dos grupos o grau de atualização certificado pela instituição ao qual encontravam-se vinculados. Dos 32 grupos de pesquisa que restaram, 12 grupos foram desconsiderados por possuírem a data de atualização anterior a 2013. Sendo assim, o estudo restringiuse a 20 grupos, dos quais foram coletadas as informações organizadas em uma planilha do Excel®. Esse procedimento viabilizou a elaboração da analise apresentada a seguir. 


\section{DADOS OBTIDOS E ANÁLISE}

O Quadro 1 apresenta as características gerais dos grupos analisados. Constatou-se que há 184 pesquisadores distribuídos entre os 20 grupos, o que perfaz uma média aproximada de nove pesquisadores por grupo. Todavia, verificou-se a existência de uma variação significativa na quantidade de pesquisadores entre os grupos, pois o grupo com maior número de pesquisadores tinha 34 e o menor apenas um.

Analisando-se a filiação institucional dos pesquisadores pertencentes aos 20 grupos, verificou-se que há um total de 16 instituições entre públicas e privadas. Há um vínculo maior de pesquisadores às organizações públicas - 13 universidades federais ou estaduais e a Fundação Oswaldo Cruz (FIOCRUZ); e duas organizações privadas. Diante do exposto, observou-se que parece haver um incentivo maior à formação de grupos de pesquisa na esfera pública. 
Quadro 1 - Grupos de pesquisa em inteligência competitiva cadastrados no diretório de grupos de pesquisa do CNPq. $\mathrm{n}=20$.

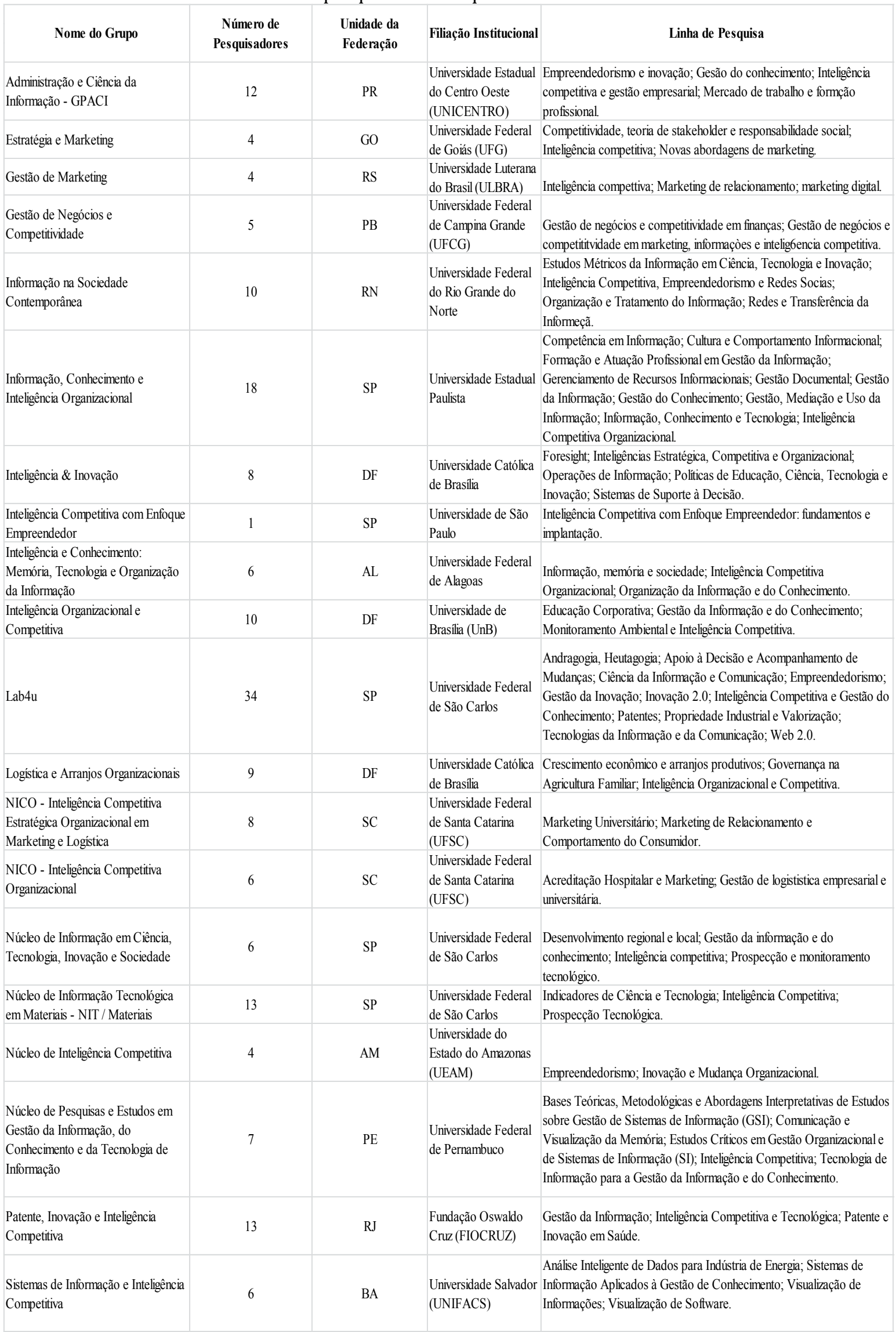


Com relação às linhas de pesquisa, a figura 2 registra os temas complementares à inteligência competitiva que figuram nas linhas de pesquisa dos grupos de pesquisa. No diagrama é possível verificar uma prevalência do termo inteligência competitiva, bem como os temas relacionados, demonstrando claramente que a inteligência competitiva é uma área interdisciplinar.

Figura 2 - Inteligência competitiva e temas relacionados nos grupos de pesquisa

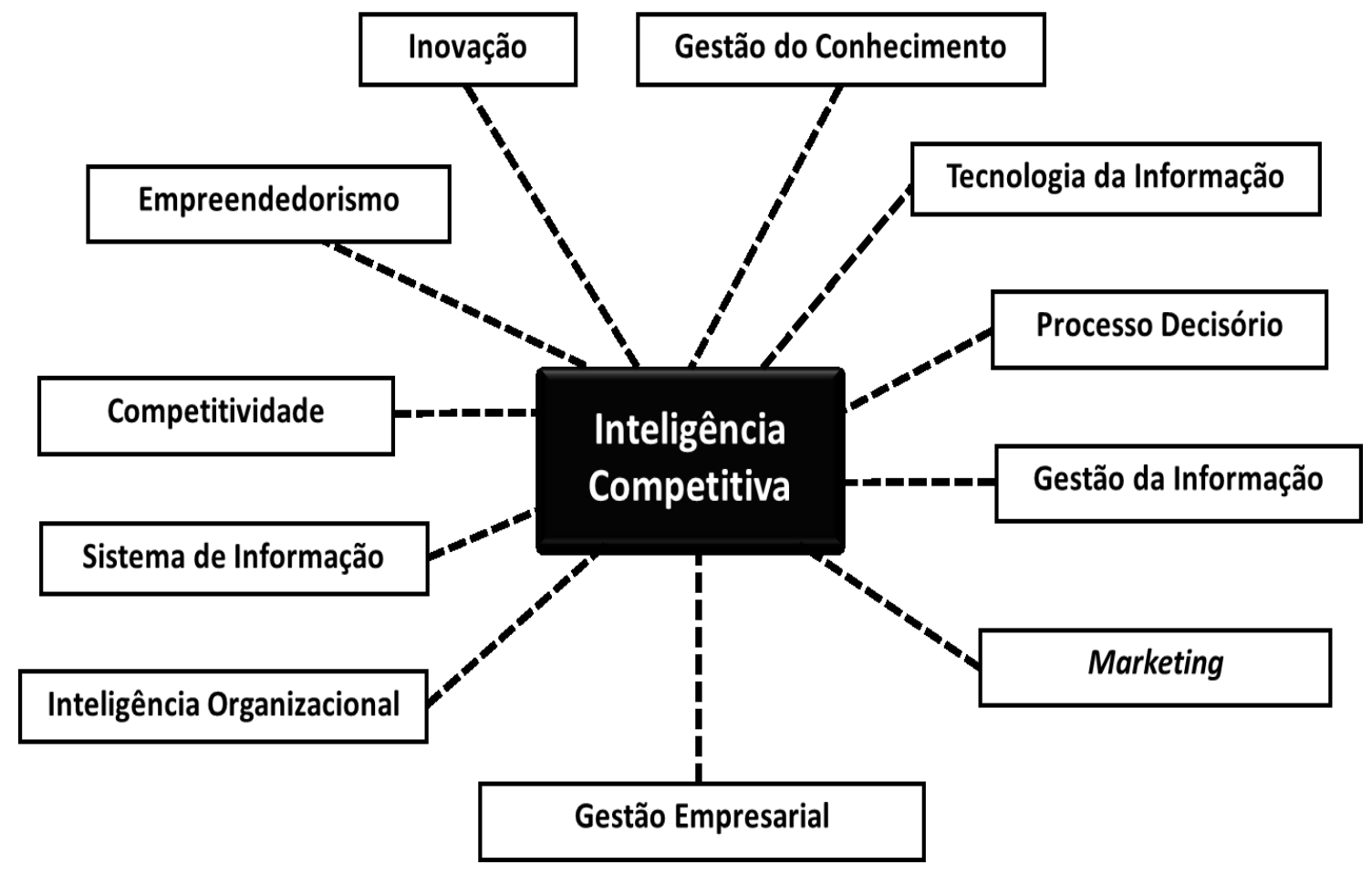

Fonte: Elaboração dos autores.

O gráfico 1 apresenta o quantitativo dos grupos de pesquisa em inteligência competitiva por unidade da federação. Nota-se que São Paulo, com os cinco grupos oriundos da esfera pública, Distrito Federal, com dois na esfera pública e uma particular e Santa Catarina, com dois na esfera pública, respondem por $50 \%$ de todos os grupos de pesquisa em Inteligência Competitiva no País.

É perceptível que nessas três unidades da federação há sempre mais de um grupo de pesquisa, diferentemente das outras unidades que possuem apenas um grupo. Também cabe ressaltar que das 27 unidades da federação, 14 não possuem grupos de pesquisa nessa área, aproximadamente 53\% do total. 
Gráfico 1 - Quantitativo dos grupos de pesquisa em inteligência competitiva por unidade da federação.

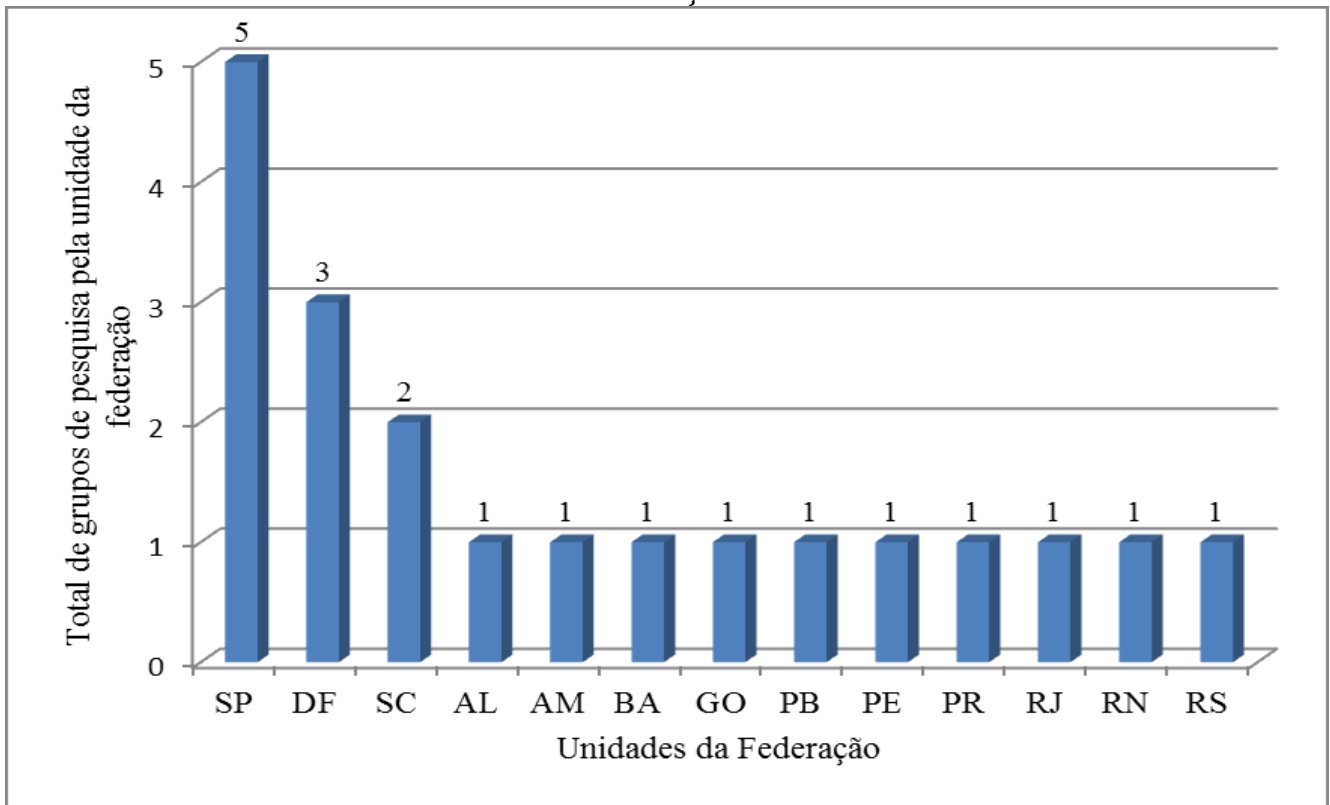

Fonte: Elaboração dos autores.

De acordo com os dados do gráfico 2, do total de 2418 artigos publicados pelos grupos de pesquisa, os cinco primeiros grupos: Lab4u (Universidade Federal de São Carlos-SP com 653 artigos); Inteligência Organizacional e Competitiva (Universidade de Brasília -DF com 272 artigos); Núcleo de Informação Tecnológica em Materiais - NIT / Materiais (Universidade Federal de São Carlos -SP com 235 artigos); Patente, Inovação e Inteligência Competitiva (Fundação Oswaldo Cruz -RJ com 224 artigos) e Informação, Conhecimento e Inteligência Organizacional (Universidade Estadual Paulista - SP com 199 artigos) publicaram 1583 artigos, o que representa $65 \%$ dos artigos publicados por todos os grupos de pesquisa analisados.

Outra análise que merece ser registrada é que a quantidade de pesquisadores por grupo tem definido o quantitativo da produção. Tal fato pode ser corroborado pela seguinte avaliação: o grupo mais produtivo com 653 artigos publicados possui 34 pesquisadores e o menos produtivo com quatro artigos publicados possui apenas um pesquisador. Esse indicador pressupõe que quanto maior for o número de pesquisadores maior será a produção. 
Gráfico 2 - Total de artigos publicados por grupo de pesquisa.

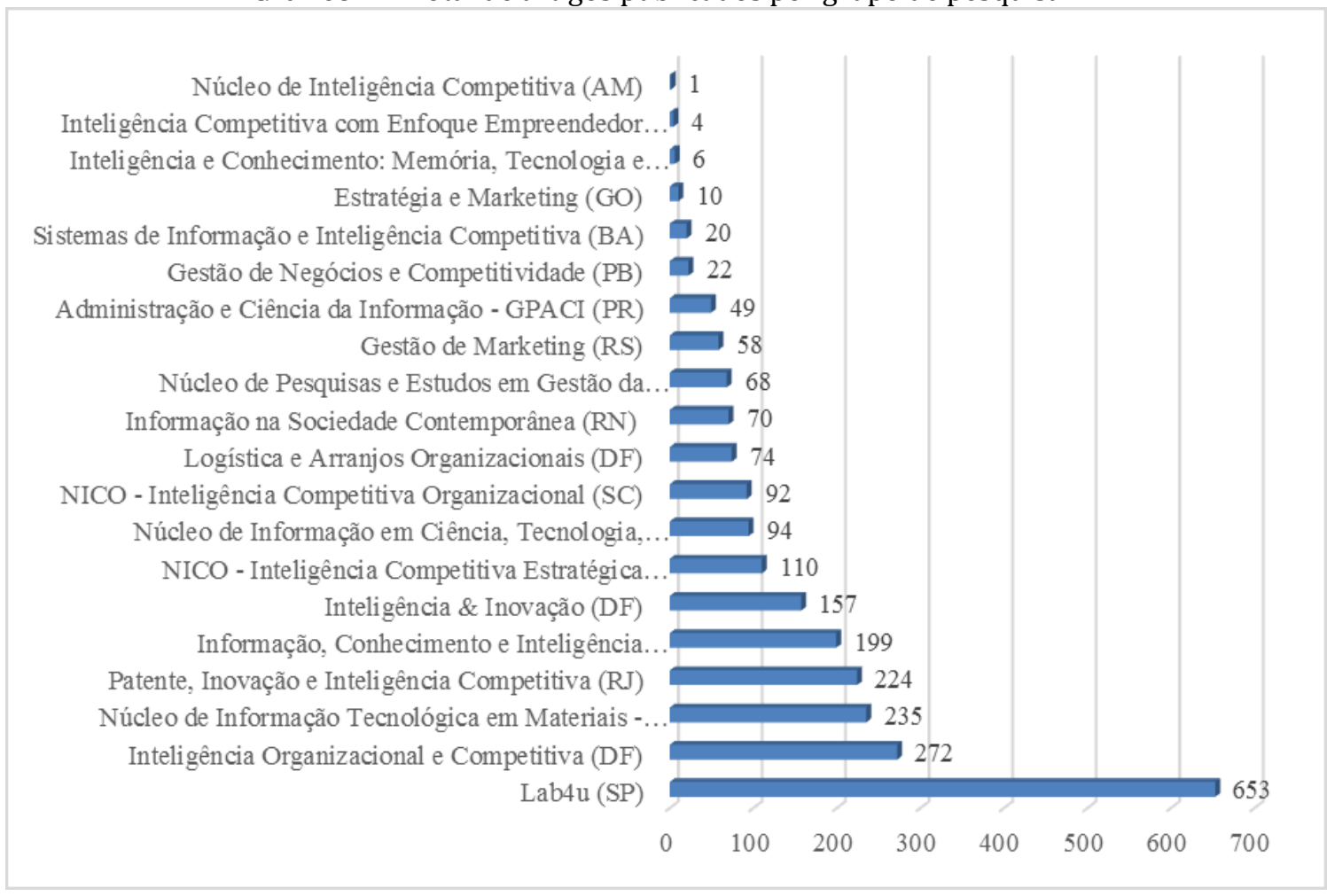

Fonte: Elaboração dos autores.

Os dados do gráfico 3, demonstram que do total de 1437 livros e capítulos de livros publicados pelos grupos de pesquisa, os cinco primeiros grupos: Lab4u (Universidade Federal de São Carlos - SP com 331 livros e capítulos); Núcleo de Informação Tecnológica em Materiais - NIT / Materiais (Universidade Federal de São Carlos - SP com 175 livros e capítulos); Informação, Conhecimento e Inteligência Organizacional (Universidade Estadual Paulista - SP com 162 livros e capítulos); Inteligência Organizacional e Competitiva (Universidade de Brasília DF com 146 livros e capítulos) e Inteligência \& Inovação (Universidade Católica de Brasília - DF com 122 livros e capítulos de livros) publicaram 936 livros e capítulos de livros, o que representa $65 \%$ dos livros e capítulos de livros publicados pelos grupos de pesquisa.

Cabe ressaltar que, também, neste quesito, o grupo de pesquisa Lab4u, com maior número de pesquisadores (34), foi o mais produtivo. 
Gráfico 3 - Total de livros e capítulos de livros publicados por grupo de pesquisa

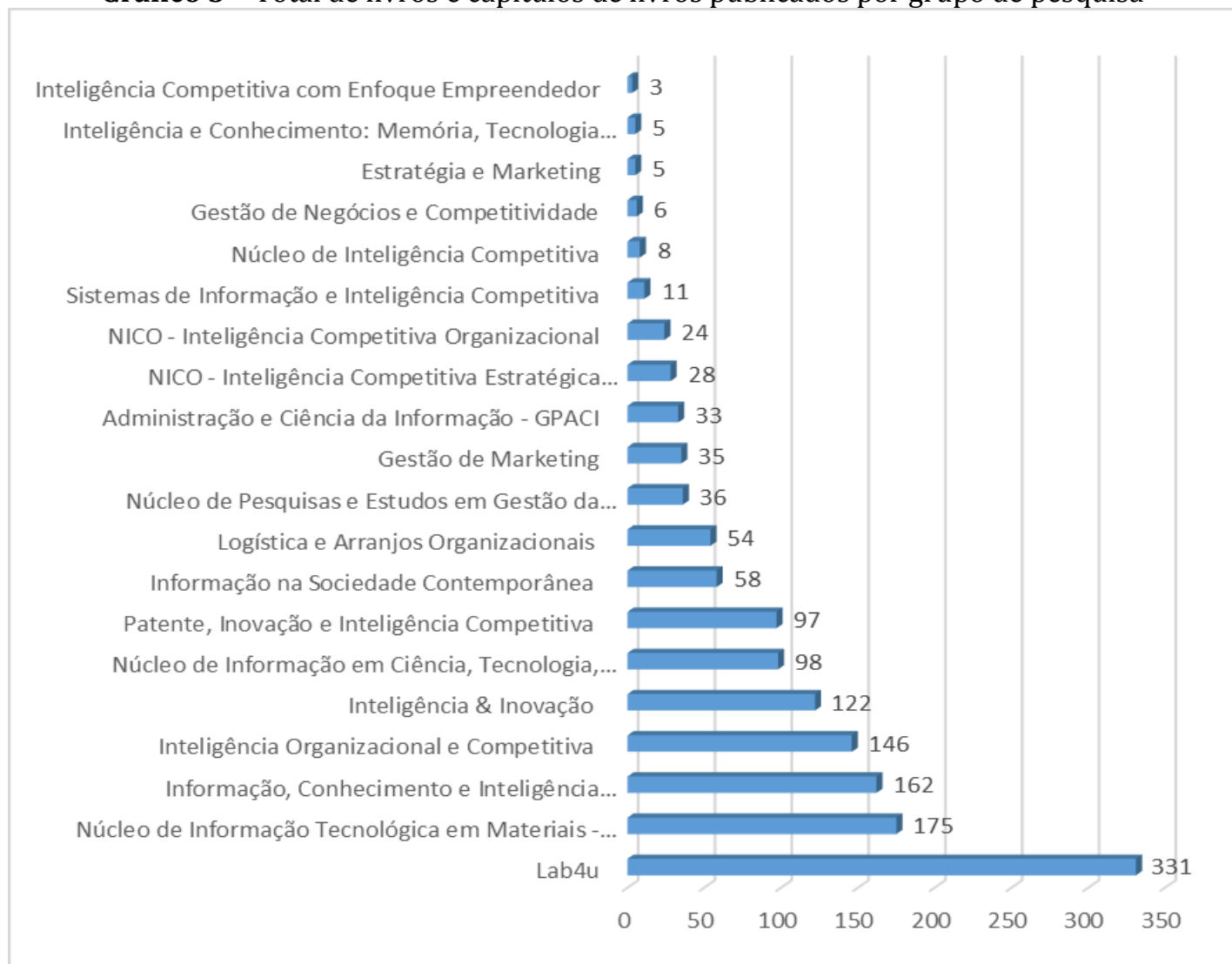

Fonte: Elaboração dos autores.

Uma análise que também é importante ser realizada ao cotejar o gráfico quatro é a quantidade de empresas associasdas aos grupos de pesquisa. Verificouse que do total dos 20 grupos, apenas sete possuem empresas associadas, totalizando $35 \%$ do universo.

Gráfico 4 - Quantidade de grupos de pesquisa em inteligência competitva que tem empresas associadas ao grupo.

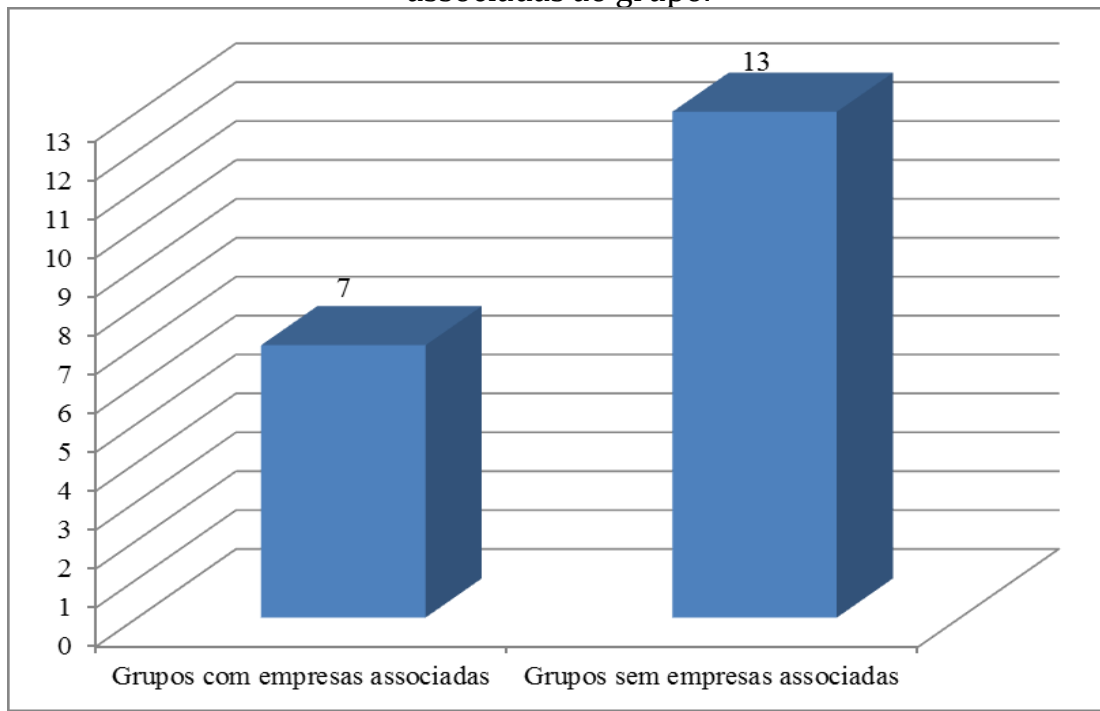

Fonte: Elaboração dos autores. 
As empresas associadas aos sete grupos são: Atalaia Palace Hotel no grupo Administração e Ciência da Informação - GPACI; Associação Comercial e Industrial de Marília no grupo Informação, Conhecimento e Inteligência Organizacional; Ministério do Desenvolvimento, Indústria e Comércio Exterior no grupo Inteligência Organizacional e Competitiva; Intelligentsia Editoração no grupo Lab4u; Empresa de Assistência Técnica e Extensão Rural do DF no grupo Logística e Arranjos Organizacionais; Instituto Nacional de Pesquisas da Amazônia, Associação Brasileira das Indústrias de Calçados e Associação Brasileira de Metalurgia e Materiais no grupo Núcleo de Informação em Ciência, Tecnologia, Inovação e Sociedade; Nortec Química S.A. e Cristália Produtos Químicos e Farmacêuticos no grupo Patente, Inovação e Inteligência Competitiva.

\section{CONCLUSÕES}

Com base nos dados coletados na pesquisa e em função das análises especificadas nos parágrafos anteriores, pode-se afirmar que o propósito da investigação foi plenamente atingido, em razão das seguintes premissas: foi possível descortinar as principais características dos grupos de pesquisa em Inteligência Competitiva constantes do Diretório dos Grupos de Pesquisa do CNPq: nomes dos grupos, números de pesquisadores, Unidades da federação, filiação institucional e linhas de pesquisa.

Por intermédio do presente estudo, conseguiu-se traçar um pequeno mapa dos linhas de pesquisa complementares ao tema da inteligência competitiva que aparecem nos grupos de pesquisa. Conforme a figura 2

à são as seguintes: gestão do conhecimento, gestão empresarial, gestão da informação, competitividade, empreendedorismo, inteligência organizacional, marketing, tecnologia da informação, inovação, sistema de informação e processo decisório.

Observou-se que a quantidade de artigos, bem como livros e capítulos de livros publicados foi diretamente proporcional à quantidade de pesquisadores por grupo, ou seja, o grupo com maior número de publicações também possuía o maior número de pesquisadores. Situação análoga pode ser constatada no grupo com 
menor número de publicações que por sua vez possuía o menor número de pesquisadores.

Outro fato curioso que se depreende da análise foi a concentração dos grupos mais produtivos em três unidades da federação, respectivamente: São Paulo, Brasília e Santa Catarina. Os quais respondem por, aproximadamente, 65\% de todas as publicações de todos os grupos de pesquisa em Inteligência Competitiva no Brasil.

Ainda hoje, dentre as 27 unidades da federação, somente 14 delas possuem grupos de pesquisa em inteligência competitiva, área de suma importância para o desenvolvimento das organizações públicas e privadas de um país que tenha como objetivo tornar-se uma referência internacional nos campos político, econômico, social e tecnológico.

Por último, é notório registrar que no quesito: empresas associadas aos grupos de pesquisa há apenas sete grupos com relacionamento empresarial. Este fato deixa transparecer a falta de articulação da pesquisa brasileira em inteligência competitiva com os setores produtivos, parecendo revelar a precariedade do modelo de inovação acadêmica como aporte de desenvolvimento para a sociedade.

Este trabalho não teve a pretensão de exaurir a análise dos temas; todavia, procurou mapear o status quo dos grupos de pesquisa de inteligência competitiva elencados no diretório dos grupos de pesquisa do País. Novos estudos bibliométricos deverão lançar luz sobre a complexidade das relações desses grupos com a capacidade de inovação ao longo do tempo para a compreensão do desenvolvimento dessa área.

\section{REFERÊNCIAS}

AMARAL, R. M. do et al. Análise da produção científica brasileira em inteligência competitiva. Encontro Nacional de Pesquisa em Ciência da Informação, 16, ENANCIB, João Pessoa, Anais, 26 a 30 out. 2015. Disponível em: <http://www.ufpb.br/evento/lti/ocs/index.php/enancib2015/enancib2015/pape r/viewFile/2782/1082 >. Acesso em: 13 ago. 2016.

CNPq. Diretório dos Grupos de Pesquisa no Brasil o que é? 2016. Disponível em: <http://lattes.cnpq.br/web/dgp/o-que-e>. Acesso em: 14 ago. 2016. 
DOU, H. J. M.; MANULLANG, S. D. Competitive intelligence: technology watch and regional development. Jacarta: MUC Publishing, 2004.

DRUCKER, P. Desafios gerenciais para o século XXI. Tradução de Nivaldo Montinguelli Jr. São Paulo: Cengage Learning, 1999.

FULD, L. The secret language of competitive intelligence: how to see through and stay ahead of business disruptions, distortions, rumors, and smoke screens. Indianapolis: Dog Ear Publishing, 2010.

GUEDES, V. L. S.; BORSCHIVER, S. Bibliometria: uma ferramenta estatística para a gestão da informação e do conhecimento, em sistemas de informação, de comunicação e de avaliação científica e tecnológica. 2005. Disponível em: <http://www.feg.unesp.br/ fmarins/seminarios/Material\%20de\%20Leitura/Bib liometria/Artigo\%20Bibliometria\%20\%20Ferramenta\%20estat\%EDstica\%20VaniaLSGuedes.pdf >. Acesso em: $17 \mathrm{dez}$. 2013.

HOFFMANN, W. A. M. Monitoramento da informação e inteligência competitiva: realidade organizacional. InCID: R. Ci. Inf. E Doc., Ribeirão Preto, v. 2, n. 2, p. 125144, jul./dez, 2011. Disponível em: ,http://www.revistas.usp.br/incid/article/view/42356/46027>. Acesso em: 13 ago. 2016.

MARTINS, A.; FERNEDA, E.; MARTINS, F. Inteligência das organizações: a organização das inteligências. Brasília: Editora Universa, 2008.

PERUCCHI, V.; ARAÚJO JÚNIOR, R. H. de. Produção científica sobre inteligência competitiva da Faculdade de Ciências da Informação da Universidade de Brasília. Perspectivas em Ciência da Informação, v.17, n.2, p.37-56, abr./jun. 2012. Disponível em: <http://www.scielo.br/pdf/pci/v17n2/a04v17n2.pdf >. Acesso em: 17 dez. 2013.

PORTER, M. Competitive advantage: creating and sustaining superior performance. New York: The Free Press, 1985.

SILVA, M. C. da; CASIMIRO, A. H. T.; DUARTE, E. N. Caracterização dos grupos de pesquisa em inteligência organizacional competitiva. Biblionline, João Pessoa, v. 12, n. 1, p. 14-25, 2016. Disponível em:

<http://www.ies.ufpb.br/ojs/index.php/biblio/article/view/27971>. Acesso em: 13 ago. 2016.

Recebido em: 07 de maio de 2015

Aceito em: 08 de agosto de 2017 